\title{
Implant Placement with Ridge Splitting and PRF Placement - A Case Report
}

\author{
Dr. Priyesh Kesharwani ${ }^{1 *}$, Dr. Dushyanth Paul ${ }^{2}$, Dr. Rahul Vinay Chandra Tiwari ${ }^{3}$, Dr. VKV Naidu Pentakota ${ }^{4}$, Dr. V K
} Sasank Kuntamukkula ${ }^{5}$, Dr. Kapil Kumar Kardwal ${ }^{6}$

${ }^{1}$ MDS Oral and Maxillofacial Surgeon, Consultant and Private Practitioner DENT-O-FACIAL Multispeciality Clinic, Mira road, Thane-Mumbai, India ${ }^{2}$ Professor, Department of Oral and Maxillofacial Surgery, Sri Sai College of Dental Surgery, Vikarabad, Telangana, India

${ }^{3}$ FOGS, MDS, Assistant Professor, Department of Oral and Maxillofacial Surgery, Sri Sai College of Dental Surgery, Vikarabad, India

${ }^{4}$ MDS, Oral and maxillofacial surgeon and implantologist, Maruthi superspeciality face,jaw and Dental clinic, Opp.RTC complex ingate, Anakapalli, Andhra Pradesh, India

${ }^{5}$ MDS, Assistant Professor, Department of Oral and Maxillofacial Surgery, Sri Sai College of Dental Surgery, Vikarabad, India

${ }^{6}$ PG Student, OMFS, Surendra Dental College \& RI, Sriganganagar, Rajasthan, India

*Corresponding author: Dr. Priyesh Kesharwani

\section{Abstract}

Ridge augmentation of the deficient alveolar ridge is often required to compensate for the bone loss and to make it suitable for an implant placement. In this case report, we followed the technique of ridge split technique with simultaneous PRF and implant placement in the anterior maxillary region.

Keywords: Implant, Ridge Split, PRF.

Copyright @ 2019: This is an open-access article distributed under the terms of the Creative Commons Attribution license which permits unrestricted use, distribution, and reproduction in any medium for non-commercial use (NonCommercial, or CC-BY-NC) provided the original author and source are credited.

\section{INTRODUCTION}

Dental implants as a treatment modality for the replacement of missing teeth have increased over the years. The favourable success rate has encouraged the clinicians to opt for dental implants as a treatment option. However, its application is limited in regions with resorbed ridges. To overcome this limitation, clinicians have suggested various pre-implant hard and soft tissue augmentation procedures to reconstruct the ridge deficiencies such as guided bone regeneration with a cancellous graft, onlay/veneer block graft, inlay grafting and ridge split [1]. Simion et al., and Scipioni et al were amongst the first to describe the of ridge expansion or split crest technique for implant placement $[2,3]$. Over the years, many modifications were advocated with or without interpositional bone grafting to augment the residual ridge.

A proper case selection and evaluation is important to achieving a successful surgical and prosthetic outcome. Split Ridge Technique is a achievable in ridges with horizontal defects ranging from 3-5 $\mathrm{mm}$ and with no indication for vertical augmentation. This $3 \mathrm{~mm}$ bone will have at least $1 \mathrm{~mm}$ of trabecular bone between the two cortical plates, which will ensure housing the implant with good surrounding blood supply. Maxillary ridges are preferred over mandibular ridge as the former has a porous trabecular pattern $[4,5]$. Various instruments such as hand instruments, microsaw or ultrasonic devices are used to perform longitudinal osteotomy on the residual ridge. To bring about ridge expansion and lateral repositioning of the buccal bone plate, osteotomes, chisels horizontal spreaders or screw spreaders are used. The wider implant bed formed between the two cortical plates is filled with bone grafts alone or in combined with barrier membranes [5].

In this case report, we described a case of horizontal ridge augmentation using ridge split and simultaneous implant placement and PRF placement in esthetic maxillary anterior region.

\section{CASE REPORT}

A 25- year old male patient reported to the hospital with a chief complaint of missing upper front teeth since 2 years. He reported a history of trauma 2 years back following which 2 upper front teeth were extracted due to poor prognosis. Since then he has been wearing a removable partial denture in the edentulous area and wants a fixed prosthesis. Clinical examination revealed missing maxillary right central and lateral incisor (Figure-1). Further examination of the edentoulous resorbed ridge revealed a thick gingival 
biotype with reduced bucco-palatal deficiency. Radiographic examination revealed $4-5 \mathrm{~mm}$ of bone width at the crest and $6-8 \mathrm{~mm}$ in the apical region (Figure-2). The treatment plan included a single step ridge split procedure with simultaneous PRF grafting along with a single implant placement. The patient consented to treatment. Bone sounding of the residual ridge showed approximately $4-5 \mathrm{~mm}$ bone width at the crest and $6-8 \mathrm{~mm}$ at the apex. The patient rinsed with a $0.12 \%$ chlorhexidine solution for a minute presurgically. Local anesthesia was administered using $2 \%$ lidocaine with 1:100,000 epinephrine. Para-crestal and vertical incisions were given from mesial of maxillary right canine to distal of maxillary left lateral incisor and a full thickness mucoperiosteal flap was reflected facially and palatally (Figure $3 \& 4$ ). Using a surgical guide, the implant position was marked in maxillary right central incisor region. Osteotomy sites were marked, ridge was split from the crest using fine chisels and gradually facial plate of the bone was expanded using tapered osteotomes with increasing diameter (Figure-5). After achieving the proper width of the bone, osteotomy was performed using sequential drilling to place a single dental implant [OSSTEM implant, dimension $3.8 \times 11 \mathrm{~mm}$ ] flushing it with the crest margin (Figure-6). Abutment was placed with $30 \mathrm{~N}-\mathrm{cm}$ of torque. To augment the expanded ridge, PRF (Platelet Rich Fibrin) was prepared fresh before placement at the surgical site. For the PRF preparation, $10 \mathrm{ml}$ of blood was drawn from patient's antecubital vein and transferred to the test-tube without anticoagulant. The blood sample was immediately centrifuged at $3000 \mathrm{rpm}$ for 10-12 minutes. After centrifugation, fibrin clot was squeezed between gauze pieces to obtain PRF membrane. The PRF membrane was placed over the surgical site (Figure-7) and primary closure of the flap was achieved using 3-0 silk sutures (Figure-8). Patient was put on a week-long course of antibiotic therapy and chlorhexidine intraoral rinses. Post op healing was uneventful.

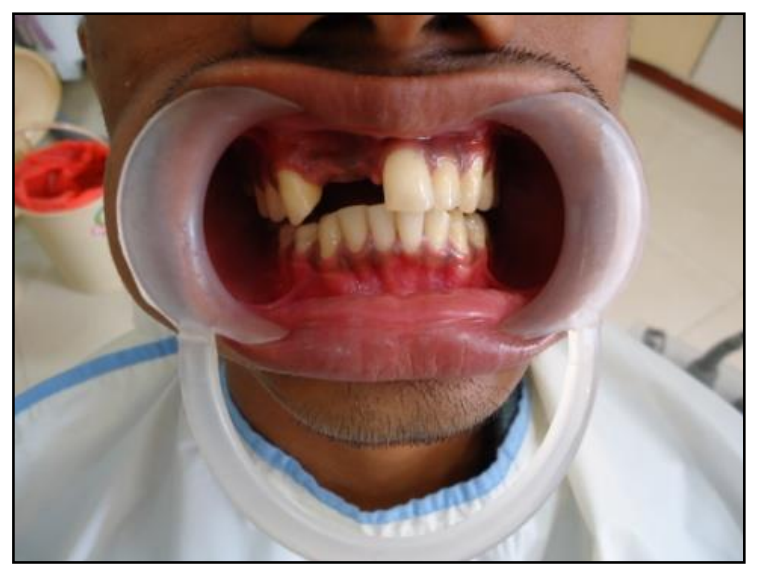

Fig-1: Pre-Op (Missing 11 \& 12)

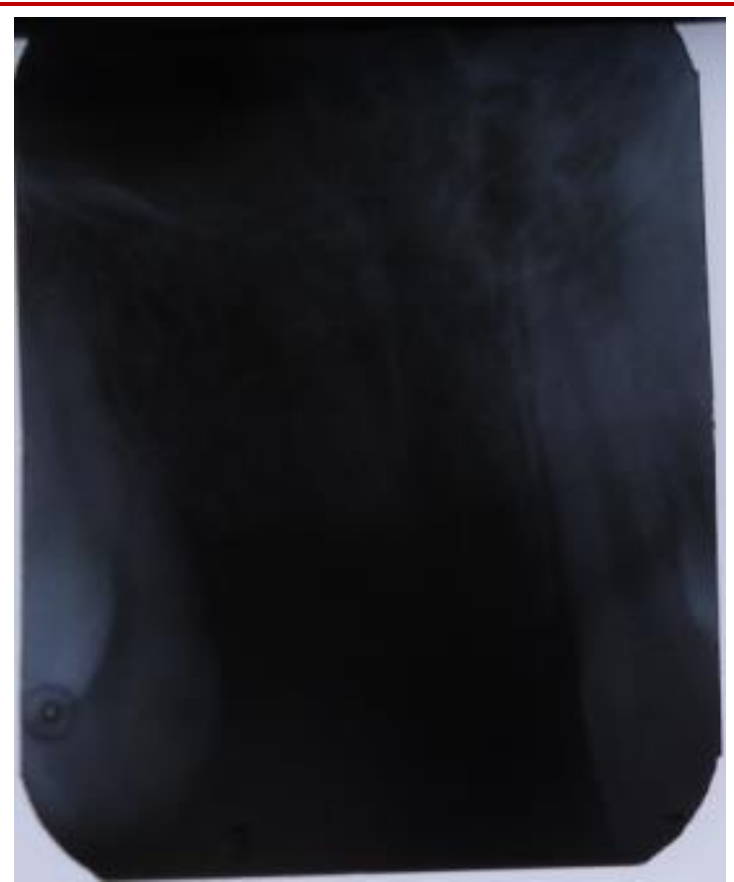

Fig-2: IOPA

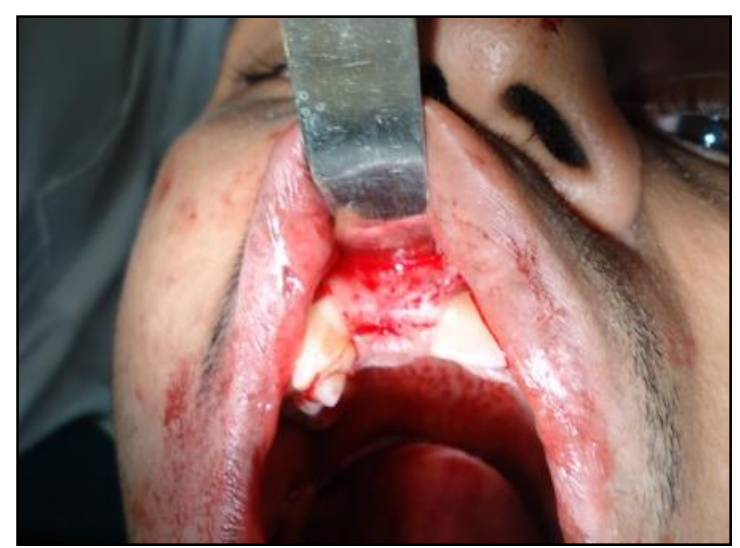

Fig-3: Reflection Of Flap

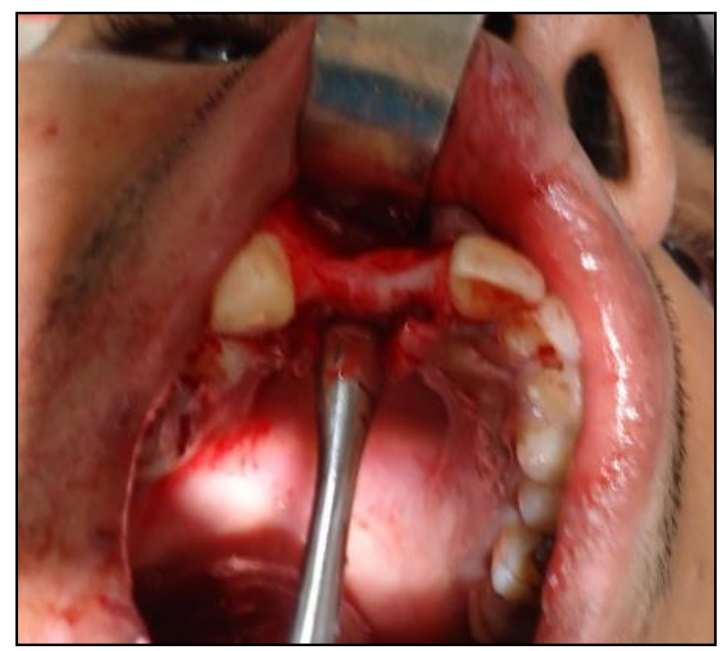

Fig-4: Ridge Exposed 
Priyesh Kesharwani et al; Saudi J Oral Dent Res, Sep 2019; 4(9): 682-685

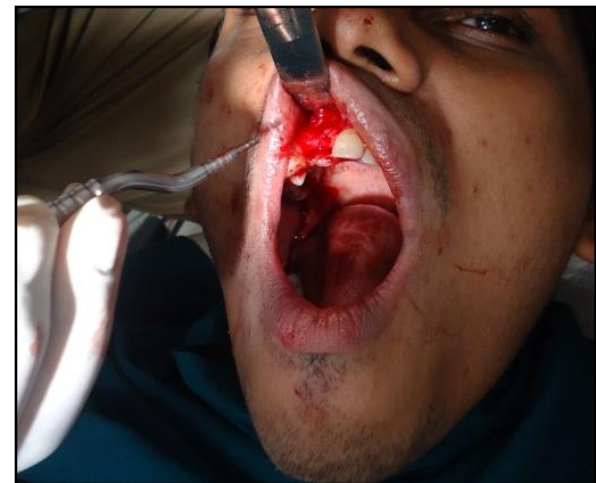

Fig-5: Ridge Splitting Done

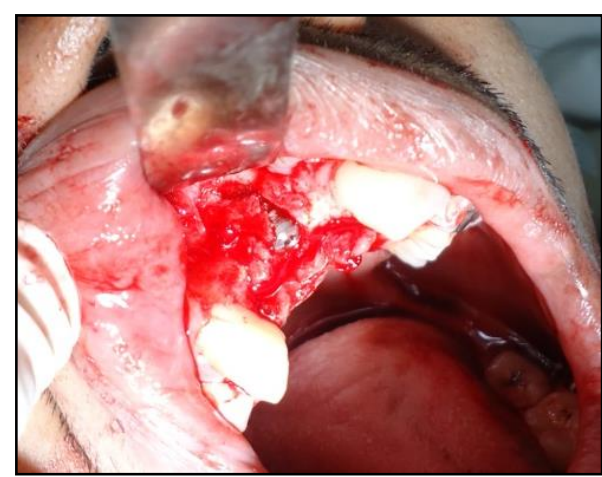

Fig-6: Implant Placed

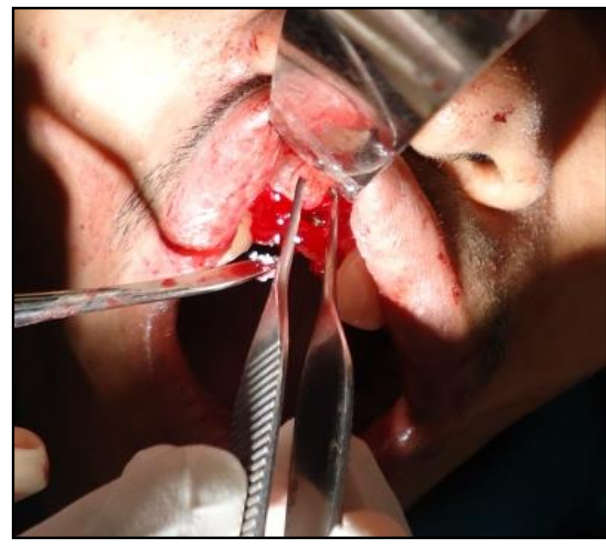

Fig-7: Packed With PRF

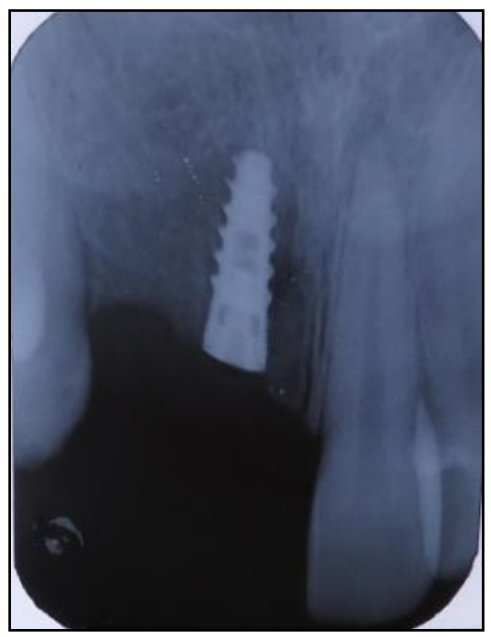

Fig-8: IOPA Showing Implant

\section{DISCUSSION}

Implant placement requires minimum of $6 \mathrm{~mm}$ ridge width along with $1-1.5 \mathrm{~mm}$ of bone surrounding the implant. Ridge augmentation reduces the stress at the crestal bone region and improves the overall prognosis of the implant supported prosthesis. In 1970s Dr. Hilt Tatum first introduced a method of ridge splitting or bone spreading using specific instruments like D-shaped graduated osteotomes/wedges and tapered channel formers. He inserted >5000 maxillary anterior implants using ridge splitting, wherein he expanded atrophic ridges $>3 \mathrm{~mm}$ for simultaneous implant placement and augmentation keeping the periosteum intact. Later, Summers and Scipioni et al., in 1994 reported a survival rate of $98.8 \%$ for over 5 years. Over the years specific instruments such as microsaws, piezosaws and specific ridge split osteotomes, were introduced to meet the needs of this technique $[6,7]$.

Ridge splitting is primarily indicated in regions of division B bone volume and D3 or D4 bone density type. Thinner ridges $(<3.5 \mathrm{~mm})$ with a softer trabecular pattern, have low elastic modulus and greater viscoelasticity show lesser risk for fracture, trauma and bone perforations. Bone expansion provides a more normal facial contour to the region [8-10]. Bone splitting does not affect the facial and palatal plates equally, the thicker palatal bone is more difficult to manipulate, therefore, the expansion process is primarily in the direction of the thinner facial plate. The bone is prepared $2-4 \mathrm{~mm}$ deeper than the final implant length using initial $2 \mathrm{~mm}$ drill; osteotomes are used to further widen the osteotomy using controlled sequential gentle tapping (about $1 \mathrm{~mm}$ for every tap) with a surgical mallet. At $3 \mathrm{~mm}$ diameter of the osteotome and depending on the amount of bone in the facial aspect, the clinical decision is made whether 3.5 or $4 \mathrm{~mm}$ diameter implant to be selected. The initial length of the osteotome, which is $3 \mathrm{~mm}$ deeper than the desired implant length, successive larger osteotome is inserted $0.5 \mathrm{~mm}$ shorter than the preceding instrument; this expands the base of the bone in a V shape rather than $\mathrm{U}$ shape. This makes it less likely to fracture the labial cortical plate, while placing the implant. The final implant is threaded into position using a slow speed, high torque physio-dispenser hand piece. Bone graft can be placed in the space of bone and implant and at the crestal region with membrane to prevent risk of crestal bone loss which also aids in bone remodeling [11-13].

In the case we reported we used PRF to fill the space between the cortical plates. It is a concentrated suspension of growth factors such as PDGF(platelet derived growth factors), transforming growth factors $\beta 1$ and $\beta 2$ (TGF $\beta 1, \beta 2$ ), vascular endothelial growth factors (VEGF), platelet derived endothelial growth factors, Interleukin $1 \& 2$, basic fibroblast growth factor $(\beta$-FGF), platelet activating factor 4 (PAF-4). The growth factors immediately bind to the transmembrane 
receptors present on the external surface of the cell membranes of wound and result in activation of gene sequence for matrix formation, cellular proliferation, osteoid production and collagen synthesis. Due to these reported benefits in the literature, we chose PRF as the grafting material $[14,15]$.

\section{CONCLUSION}

Ridge split technique is one of many methods available for ridge augmentation in deficient alveolar ridges, is advocated in cases with $>3.5 \mathrm{~mm}$ ridge width. Case selection and bone evaluation are important before proceeding with this method of augmentation.

\section{REFERENCES}

1. Aghaloo, T. L., \& Moy, P. K. (2007). Which hard tissue augmentation techniques are the most successful in furnishing bony support for implant placement?. International Journal of Oral \& Maxillofacial Implants, 22(7), 49-70.

2. Simion, M., Baldoni, M., \& Zaffe, D. (1992). Jawbone enlargement using immediate implant placement associated with a split-crest technique and guided tissue regeneration. International Journal of Periodontics \& Restorative Dentistry, 12(6):462-473.

3. Scipioni, A., Bruschi, G. B., \& Calesini, G. (1994). The edentulous ridge expansion technique: a five-year study. International Journal of Periodontics \& Restorative Dentistry, 14(5), 14:451-1459.

4. Tolstunov, L., \& Hicke, B. (2013). Horizontal augmentation through the ridge-split procedure: a predictable surgical modality in implant reconstruction. Journal of Oral Implantology, 39(1), 59-68.

5. Lakshman Dene, D. D. S., \& Condos, S. (2010). Ridge expansion and immediate implant placement in the esthetic zone. New York State Dental Journal, 76(2), 28.

6. Mechery, R., Thiruvalluvan, N., \& Sreehari, A. K. (2015). Ridge split and implant placement in deficient alveolar ridge: Case report and an update. Contemporary clinical dentistry, 6(1), 94.
7. Papathanasiou, I., Vasilakos, G., Baltiras, S., \& Zouloumis, L. (2014). Ridge splitting technique for horizontal augmentation and immediate implant placement. Balkan Journal of Dental Medicine, 18(1), 41-47.

8. Coatoam, G. W., \& Mariotti, A. (2003). The segmental ridge-split procedure. Journal of periodontology, 74(5), 757-770.

9. Arora, V., \& Kumar, D. (2015). Alveolar ridge split technique for implant placement. Medical journal, Armed Forces India, 71(Suppl 2), S496.

10. Shaik, L. S., Meka, S., Kattimani, V. S., Chakravarthi, S. P., Kolli, N. N. D., Lingamaneni, K. P., ... \& Tiwari, R. (2016). The effect of ridge expansion on implant stability in narrow partially edentulous ridges-a preliminary clinical study. Journal of clinical and diagnostic research: JCDR, 10(9), ZC28.

11. Agrawal, D., Gupta, A. S., Newaskar, V., Gupta, A., Garg, S., \& Jain, D. (2014). Narrow ridge management with ridge splitting with piezotome for implant placement: report of 2 cases. The Journal of Indian Prosthodontic Society, 14(3), 305-309.

12. Tolstunov, L., \& Hicke, B. (2013). Horizontal augmentation through the ridge-split procedure: a predictable surgical modality in implant reconstruction. Journal of Oral Implantology, 39(1), 59-68.

13. Sohn, D. S., Lee, H. J., Heo, J. U., Moon, J. W., Park, I. S., \& Romanos, G. E. (2010). Immediate and delayed lateral ridge expansion technique in the atrophic posterior mandibular ridge. Journal of Oral and Maxillofacial Surgery, 68(9), 2283-2290.

14. Bassetti, M. A., Bassetti, R. G., \& Bosshardt, D. D. (2016). The alveolar ridge splitting/expansion technique: a systematic review. Clinical oral implants research, 27(3), 310-324.

15. Boora, P., Rathee, M., \& Bhoria, M. (2015). Effect of platelet rich fibrin (PRF) on peri-implant soft tissue and crestal bone in one-stage implant placement: a randomized controlled trial. Journal of Clinical and Diagnostic Research: JCDR, 9(4), ZC18. 